\title{
Función y simbología del agua en La guitare de Michel del Castillo ${ }^{1}$
}

\author{
Morales-Peco, Montserrat $^{a}$; Pisa-Cañete, María Teresa ${ }^{b}$ \\ a Universidad de Castilla La Mancha, Monserrat.Morales@uclm.es; b Universidad de Castilla La Mancha, MariaTeresa.Pisa@uclm.es
}

\begin{abstract}
Resumen
Diferentes elementos acuáticos intervienen en la recreación del decorado donde tienen lugar las desventuras del protagonista de La guitare de Michel del Castillo (1958). Este análisis se propone identificar e interpretar el valor simbólico del mar y de la lluvia en el futuro trágico del protagonista. El mar, omnipresente en el paisaje gallego que sirve de marco a la acción, es presentado, por un lado, como una divinidad femenina maléfica y violenta y, por otro lado, como una sirena seductora y peligrosa. La lluvia contribuye, igualmente, a recrear ese espacio carcelario que abruma el alma del protagonista. Los monótonos días de lluvia conducen, sin remedio, a un hastío eterno. El protagonista, rechazado y asilado por todos, debido a su deformidad y fealdad, se convierte en víctima del drama de la diferencia. Su guitarra, en la que pone todas sus esperanzas para alcanzar una comunión con los otros, tampoco podrá vencer a las fuerzas mortíferas de su destino. En La guitare Michel del Castillo presenta un relato trágico sobre el hecho de ser diferente y el rechazo que eso provoca. De este modo reflexiona también sobre la identidad y la crisis de la identidad de los exiliados, como él mismo, de origen español y exiliado en Francia.
\end{abstract}

Palabras clave: xenongrafía; crisis de identidad; agua; mar; rechazo.

\section{Résumé}

Plusieurs éléments aquatiques servent à créer le contexte spatial où ont lieu les mésaventures du nain difforme protagoniste de La guitare de Michel de Castillo (1958). Cette analyse vise à identifier et interpréter la valeur symbolique de la mer et de la pluie dans le devenir tragique du protagoniste. La mer, omniprésente dans le paysage galicien où se déroule l'action, est présentée, d'un côté, comme une déesse malfaisante et violente et, d'un autre côté, comme une sirène séduisante et dangereuse. La pluie contribue, également, à créer cette ambiance carcérale qui épuise l'âme du protagoniste. Les monotones jours de pluie mènent, fatalement, à une lassitude éternelle. Le protagoniste, refusé et isolé par tous, à cause de sa difformité et sa laideur, devient victime de la tragédie de la différence. Sa guitare, en laquelle il place tous ses espoirs pour atteindre la communion avec les autres, ne pourra pas non plus vaincre les forces meurtrières de son destin. Dans La guitare, Michel del Castillo présente un récit tragique sur le fait d'être différent et le refus que cela suscite. En faisant cela, il réfléchit aussi sur l'identité et la crise de l'identité des exilés, comme lui-même, d'origine espagnole et exilé en France.

Mots-clés: xénographie; crise d'identité; eau; mer; refus.

\begin{abstract}
The spatial context in which the misfortunes of the main character take place includes several aquatic elements. La guitare is a novel written by Michel del Castillo in 1958. This analysis aims to identify and to evaluate the symbolic value of the sea and the rain in the tragic destiny of the main character. The sea, which is omnipresent in the Galician landscape where the action takes place, is presented, on the one hand, like an evil and violent goddess and, on the other hand, like a seducer and dangerous Siren. Besides, the rain contributes to create that prisonlike space which exhausts the soul of the main character. The monotonous rainy days lead him, inevitable, to a never-ending foredoom. The main character, rejected and isolated by everybody, due to his deformity and ugliness, becomes a victim of the tragedy of being different.
\end{abstract}

\footnotetext{
${ }^{1}$ Para la elaboración de este trabajo se ha contado con el apoyo del proyecto de investigación «Crisis y cambios sociales: impactos en el proceso de modernización en la España del siglo XX» (HAR2014-54793-R), financiado por el Ministerio de Economía y Competitividad.
} 
His guitar, in which he places all of his hope to reach the communion with the others, will not be able either to defeat the deadly forces of his faith. In La guitare Michel del Castillo presents a tragic story about the fact of being different and the subsequent rejection. Thus, he also considers the identity crisis and the identity crisis of the exiled people, like him, who was born in Spain but had to go into exile in France.

Keywords: xenography; identity crisis; water; sea; rejection.

\section{Introducción}

La guitare pertenece a ese grupo de novelas que Michel del Castillo ambienta en España. Sin duda, el exilio forzado en 1939, cuando apenas contaba cinco años, debido a la militancia de su madre, Isabel del Castillo, en defensa de la República durante la guerra civil (Dorenlot, 1992: 4-5), al que sucedió posteriormente el exilio voluntario en 1953 del joven de veinte años reacio a la dictadura (Dorenlot, 1992: 14), ha debido afianzar en él ese sentimiento de escisión con el que había convivido desde su nacimiento al sentirse pertenecer a dos razas, a dos mundos distintos, Francia por ascendencia paterna y, por la materna, España. En La guitare se refleja una Galicia de mentalidad retrógrada y arcaica, marcada por las supersticiones y las creencias populares, pero también por la miseria y la amenaza incesante de la muerte, causas ambas de tristeza, de nostalgia, de hastío, es decir de morriña. El trasfondo psíquico del protagonista, que él mismo revela a través de una narración en primera persona, coincide con esta alma gallega. Se trata de un enano deforme y maltrecho que vive sumido en la desolación al inspirar en el pueblo repulsión, odio y temor, de donde resulta la tragedia de su exclusión y separación y el tormento de la incomprensión que se eleva ante la mirada hostil del otro. En perfecta sintonía y correspondencia con el sentir gallego y, en especial, con el del protagonista, se despliega un paisaje, dominado por un agua oscura y gris, violenta, maléfica y fúnebre, que se manifiesta a través de diversas modulaciones, como la bruma, la lluvia y el mar. Estos elementos acuáticos del paisaje gallego, espejo reflectante del ser profundo y del devenir existencial del personaje, que se describe en La guitare con un evidente lirismo, constituyen precisamente el objeto de análisis del presente análisis.

\section{El mar y la muerte: de la figuración de la feminidad terrible a la ofelización}

El mar es para el gallego de La guitare una presencia hostil e inquietante. El narrador insiste en su aspecto agitado, desencadenado, violento y tempestuoso. Su terrible estruendo turba la existencia de estos hombres. Es una fuerza destructiva, maléfica y mortífera, «una constante amenaza» de muerte: «Il faut être d'ici et savoir toute proche la mer qui menace sans cesse les vies de nos parents les plus chers [...] Elle est le Danger» (Del Castillo, 1984: 113). La peculiar orografía de la costa gallega con sus acantilados desgarrados, perforados y sus peñascos segregados y aislados metaforiza la brutalidad de las aguas y esa lucha salvaje e incesante entre el mar y la tierra («Il y a [...] les rochers qui luttent contre la mer» [Del Castillo, 1984: 17]). Las aguas se obstinan en roer los acantilados y en engullir a los hombres.

El imaginario colectivo gallego representado en La guitare caracteriza al mar a través de una combinación de atributos que lo transfiguran en una feminidad terrible, una especie de reencarnación de una Lorelei vengativa. Lo que ciertamente lo emparenta a la Lorelei de Clemens Brentano (creador de este mito literario en una balada titulada Lore-lay, de 1801), la figura de la enamorada abandonada y rechazada, que acaba arrojándose de lo alto de una roca a las aguas y convirtiéndose en un espíritu maléfico estrechamente vinculado al medio acuático y al peñasco, desde donde, por despecho y venganza («Car tout doit disparaître/Puisque lui m’est infidèle» [Derche, 1962: 165]), atrae, con la seducción de su belleza, con sus encantamientos y con la fuerza de su mirada, a los hombres a la muerte, haciéndoles desaparecer bajo el oleaje. Ciertamente, el parentesco del mar con esta feminidad terrible se manifiesta en las canciones que el pueblo gallego entona durante la Fiesta de las Aguas: «Un nouveau chant me parvint. Il y était question d’un beau jeune homme dont la mer s'était éprise et qui s'était donné à la terre. Jalouse des femmes heureuses, la mer fauchait depuis lors, pour se venger, les jeunes mâles intrépides» (Del Castillo, 1984: 120). Y está presente también en la imaginación de Gaixa, la nodriza y criada del enano, algo bruja y muy supersticiosa, que ofrece al joven, antes de que este pueda contemplarlo en persona, la feminización del mar en una enamorada celosa: 
Elle poussait de longs soupirs, ne maudissait plus les marins menacés par une mer jalouse, il lui arrivait au contraire de les plaindre.

-Les pauvres !... grommelait-elle. La mer, aujourd'hui, veut les attirer au fond. Ils doivent se sentir seuls et inquiets, livrés à cette énorme femelle jalouse... (Del Castillo, 1984: 95).

Asimismo, el narrador describe el paisaje marítimo gallego a través de una constelación de imágenes que remiten al mito de la sirena, con la que, por otra parte, acaba fusionándose la Lorelei, en especial, en determinadas reescrituras del mito, como en la de Heine. En la Odisea, las sirenas ejercen una poderosa fascinación sobre los navegantes no sólo con el canto (Odisea, XII, 37 y ss.), sino también con la voz, cuya elocuencia puede comprobar Ulises (Odisea, XII, 184-192). Según Erika Bornay, el significado etimológico, probablemente semítico, de la palabra «sirena» es «mujer que lía a los hombres con mágicas melopeas» (2001: 275). Por otra parte, toda una serie de imágenes confluyen en la erotización de las aguas, movidas por un apetito sexual insaciable que, además, resulta nefasto pues mata. El mar es imaginado como un ser en celo permanente, bajo la entrega desinhibida de pulsiones instintivas que son signo inequívoco del dominio de la Bestia:

La mer... Il te faut l'imaginer ici violente, mais amoureuse, telle une divinité de la mythologie. Elle lèche les rochers de son écume blanche, rampe, glisse, s'insinue, monte, descend, remonte: elle caresse de ses longues lames l'âpre et mâle rocher, lui parle à l'oreille et, dépitée enfin, se brise dans un râle d'amour comme le cœur se brise, dit-on, de désir inassouvi. Mais elle n'est pas vaincue. Elle revient à la charge et réussit à pénétrer et à briser ce mâle qui la repousse (Del Castillo, 1984: 17).

Encarna así una líbido desmesurada, devoradora y mortífera, que es uno de los atributos de la femme fatale, especialmente de aquella recreada en la literatura de finales del siglo XIX (Dottin-Orsini, 1993: 162-173). De hecho se ha atribuido también esta agresividad sexual a la sirena en múltiples de sus figuraciones iconográficas finiseculares, como ya ha destacado Bram Dijkstra (1994: 257): «agresivas, depredadoras, guiadas por la incesante necesidad sexual de la ninfómana».

Esta ensoñación del mar como feminidad terrible aparece en especial en las canciones del pueblo y en las historias de Gaixa. Sin duda, con ello el autor pretende ofrecernos una visión de una sociedad, la gallega, anclada aún en un cierto primitivismo medieval que confiere un lugar importante a lo sobrenatural, a las supersticiones, a los ritos y a la magia negra. Pero, por otra parte, para el narrador testigo y espectador de la Fiesta de las Aguas, esas canciones y leyendas no sólo son una forma de explicar los enigmas de la existencia humana, en concreto el misterio de la muerte, sino también, y sobre todo, constituyen una forma de enaltecer al ser humano que, por esta presencia obstinada de la muerte, toma consciencia de su mísera condición y de su impotencia. Ciertamente, estas historias son capaces de devolverle su dignidad, sentimiento muy arraigado en el pueblo, pues en ellas se muestra capaz de despertar el deseo e incluso los celos de la muerte misma y de desafiarla hasta cuando todo parece perdido para él:

Je ne sais que penser de ces paroles. Je n'en pense rien. [...] Mais j'aime ces interprétations précises des aspects mystérieux de la vie. J'aime surtout cet esprit de notre terre qui ne veut s'accommoder ni de son destin ni de ses dieux. Il me plaît de constater en cela combien est inné, chez notre peuple, le sens de la dignité humaine. C'est un esprit qui suscite des Forces puissantes contre lesquelles l'homme doit lutter. Là est l'important: partout sont toujours deux adversaires prêts à lutter l'un contre l'autre (Del Castillo, 1984: 120-121).

Las leyendas sobre el mar constituyen un reflejo del ser martirizado del enano, víctima de un mundo violento y hostil donde no hay cabida para la diferencia. Como el mar, el enano también busca esa comunión con los demás, pero encuentra el rechazo y, como el mar, ofrece a los demás un aspecto monstruoso, causa de su aislamiento e incomprensión: «Moi, j'ai toujours vécu à l'écart [...]. Si tu avais été à ma place et que tu te fusses vu toujours repoussé, toujours abandonné, toujours nargué, qu'aurais-tu fait ?» (Del Castillo, 1984: 20). 
Por otra parte, de la misma forma que los hombres buscan, mediante la celebración del rito de las Aguas y la entonación de baladas y cantinelas, medirse con su Destino, con la Muerte, con el Mar, como medio para exorcizar el Mal («les vrais acteurs, c'étaient eux-mêmes et la Mer. L’Homme et la Mer. Ils se mesuraient. Ils luttaient pendant douze mois l'un contre l'autre et, au bout de ces douze mois, ils se défiaient [...]» [Del Castillo, 1984: 122]), así también el enano, tocando a la guitarra la pieza que revela su alma verdadera e ignorada, intentará desafiar al Hombre, medirse con él para finalmente tratar de vencer la incomprensión de que es víctima: «J'allais jouer pour eux - en un geste aussi symbolique que ceux qu'ils accomplissaient au bord de l'eau. Nous allions nous défier, comme ce même jour, la Mer et les Hommes» (Del Castillo, 1984: 123). Se establece así en la novela un estrecho paralelismo entre la Fiesta de las Aguas y la guitarra (a la que el enano llama Linda), como también entre el mar y el protagonista.

El medio marítimo contrasta, a su vez, con la naturaleza carcelaria en la que transcurre la penosa y amarga vida del enano. Frente al espacio reducido (de no más de cuarenta kilómetros) y circunscrito, cercado por las colinas y la bruma, el mar representa un más allá inmenso y sin límites, ofreciéndole la ensoñación de la libertad anhelada: «Je rêvais de liberté. Je me demandais comment pouvait être la mer que je ne jamais vue et que j’aimais d'amour avant de la connaître» (Del Castillo, 1984: 34). Asimismo, procura también descanso y paz a su alma, atormentada por tantos sueños y aspiraciones frustrados (ser reconocido como quien realmente es, ser bello, bueno y normal, ser amado, ser finalmente un «hombre»...): «Auprès d'elle un nain monstrueux peut trouver le repos. Le repos, c'est de pouvoir ne plus rêver. Et j'étais las de rêver» (Del Castillo, 1984: 65). El agua se convierte, por tanto, en la percepción del enano, en un «elemento deseado». Encontramos aquí la expresión del complejo de Ofelia señalado por Bachelard que confiere al agua el valor simbólico de una invitación a morir para «alcanzar uno de los refugios materiales elementales» (Bachelard, 1994: 68).

En la Fiesta de las Aguas, el imaginario del mar también sufre una evolución. De ser ensoñado como una femme fatale, como un adversario todopoderoso y funesto con el que se mide el hombre y al que este se atreve a lanzar un desafío («Ils venaient au bord de cette eau réaffirmer leur résolution et leur courage, se mesurer au Destin» [Del Castillo, 1984: 122]), es finalmente percibido como la imagen de una feminidad bella y pura: «Ils plaignaient cette belle femelle blanche et verte, si noble d'avoir été délaissée» (Del Castillo, 1984: 123), a la que los participantes en el ritual engalan con coronas y guirnaldas de flores, en un entorno natural de un extraordinario atractivo que recuerda sobremanera la muerte de Ofelia en Hamlet y las posteriores representaciones de la hermosa joven yaciente:

La nuit tomba [...] Une nuit faite d'étoiles, de lune, de reflets sur la mer, de paix sur la terre et de nostalgies dans l'âme. Sur la petite plage, les vagues venaient étaler leurs belles parures d'argent et d'écume [...] les femmes qui ont perdu quelqu'un des leurs avancent dans l'eau et posent sur les flots de longues gerbes de fleurs [...] Et les hommes chantent, de leurs voix graves et tristes:

Pour que Tu sois belle et parée,

Comme nous les sommes pour Toi... (Del Castillo, 1984: 126-127).

Ello contribuye a recrear la imagen de la «muerte [...] bella, de la muerte florida», que interviene, según Bachelard, en la configuración del complejo de Ofelia (1994: 98). Esta ofelización del mar que se desprende de los gestos del ritual limpia la muerte de su rostro maléfico, terrible y monstruoso e invita a mirarla con otros ojos. Y en la Fiesta de las Aguas la ofelización del elemento acuático también se acompaña del llanto por el que el oficiante comunica con el dolor del mar, que le ofrece ahora el rostro noble de la amada abandonada. Por este ritual la muerte se humaniza y se acerca al hombre, lo que propicia la serena reconciliación final entre ambos, otra forma de redimir el mal: «C’est l'instant unique. Celui de la réconciliation. Le pacte d'alliance de ceux qui souffrent de solitude ou d'amour. C'est le moment où le cycle de la vie et de la mort se referme sur lui-même, à travers l'amour purificateur» (Del Castillo, 1984: 127).

Un nuevo paralelismo se establece entre esta nueva ensoñación del mar y el destino del deforme protagonista. Precisamente en este momento del rito, cuando el pueblo trata de reconciliarse con la muerte/el mar, el enano tratará también de buscar la comprensión de su comunidad, intentando desvelar, con ayuda de la guitarra, Linda, su verdadera alma sensible, noble y atormentada que dista mucho del monstruo peligroso que todos ven en él. Y su melodía que expresa con exaltación su desesperanza aparece en el relato acompañada por el «lamento eterno» del mar, en perfecta sintonía, 
ofreciéndose este como elemento coral de aquel: «Aucun bruit ne venait troubler mon récital, sauf celui de la mer toute proche, qui m’accompagnait de son éternelle plainte brisée» (Del Castillo, 1984: 130).

\section{La lluvia: compañera de la muerte y causa de hastío}

La lluvia aparece asociada a la muerte desde el principio de la novela. En efecto, cuando la madre y el padre del protagonista mueren, la lluvia y la bruma están presentes. De igual modo, Gaixa es asesinada «poco antes de Navidad» y encuentran su cuerpo una mañana en la que nevaba (Del Castillo, 1984: 98). Resulta significativo, también, el hecho de que la noche en la que a él le queman y desfiguran la cara es una noche de lluvia y bruma.

En las noches de tormenta el mar está más revuelto, causando el naufragio de las barcas de pescadores. Esto es lo que ocurrió la noche en la que la madre del protagonista agonizaba sola en su cama («Il pleuvait et le vent hurlait» [Castillo, 1984: 27]). La madre del protagonista murió cuando este contaba sólo con dos años, mientras que su padre falleció cuando él tenía dieciocho años. Del día del entierro de su padre el narrador sólo recuerda la bruma, que en Galicia, junto a la niebla, suelen acompañar a la lluvia. Además, el narrador hace alusión, por primera vez, al carácter de irrealidad que adquieren las cosas cuando son cubiertas por la bruma o la lluvia: «Mais je ne me souviens de rien, sauf de la brume qui me le rendait presque irréel» (Del Castillo, 1984: 42).

La lluvia se convierte en cómplice de la tragedia que tiene lugar para el protagonista cuando decide escaparse para ir a una fiesta: «Je pris une lanterne et partis dans la nuit et le brouillard. Il pleuvait. La brume m’enveloppait. J'avais du mal à m’orienter, ne distinguais plus rein devant moi. Le vent hurlait et, lorsqu'il soufflait plus fort, la pluie me giflait» (Del Castillo, 1984: 51). En efecto, la niebla y la lluvia se presentan como obstáculos en su camino, pues hacen que se desoriente, tiene problemas para andar por los campos mojados (debido a sus cortas piernas), siente frío y termina por perderse. Él cree que está salvado al reconocer la casa de uno de los campesinos que trabajan en sus tierras. Sin embargo, la mujer del granjero, al ver al que todos consideran como un monstruo, se asusta y le tira a la cara el contenido hirviendo de una marmita. La lluvia de agua del exterior se transforma en lluvia de fuego; un fuego que le produce graves quemaduras y que lo convertirán en un ser todavía más feo (Del Castillo, 1984: 53), hasta el punto de que él se asusta de su propia imagen y ya nunca más se mirará en un espejo. El narrador enfatiza su propia fealdad al compararse con los dibujos de seres desfigurados de Goya: «Mais j’étais devenu encore plus laid, j’étais devenu hideux. Je faisais songer à ces dessins de Goya qui vous donnent le frisson et comme un avant-goût de l'enfer. Je me faisais peur et n'osais plus jamais me regarder dans un miroir» (Del Castillo, 1984: 53).

Pero la muerte que más afectó al narrador fue la de Gaixa. Una mañana, al no verla en la granja, ordenó que fueran a buscarla y la encontraron muerta sobre la tumba de su padre; había sido lapidada. Es la única vez en la novela en la que el narrador dice que nieva. Entre la gente del lugar empezó a extenderse una leyenda sobre Gaixa: «On raconta que Gaixa allait la nuit déterrer des cadavres, voler leurs ossements et que Dieu, ce soir-là, avait fait pleuvoir des pierres sur sa tête» (Del Castillo, 1984: 98). En este uso figurativo del verbo llover se produce una total identificación de la lluvia con la muerte. Destaca, sin embargo, la presencia de la nieve, que es el elemento acuático que mejor desempeña el papel purificador propio del agua, como afirma Durand: «[l’]eau lustrale par excellence qu'est la neige purifie par la blancheur comme par le froid. [...] L’eau lustrale qui fait vivre par-delà le péché, la chair et la condition mortelle» (1992: 194). Así, la muerte de Gaixa, injustamente asesinada a manos de unos verdugos crueles, es dignificada gracias a las cualidades redentoras de la nieve. Solo Gaixa, la mujer que crió al protagonista y que siempre fue su protectora y fiel compañera, que estuvo junto a él tanto en los reveses del destino como en las alegrías, será digna de una muerte acompañada de nieve, mostrando así su triunfo sobre las aguas fúnebres.

El narrador, sin embargo, no será acompañado por la nieve en su lecho de muerte sino, de nuevo, por la lluvia. Del mismo modo que la lluvia estuvo presente esa noche de la fiesta, en la que el narrador sufrió una muerte simbólica, la noche en la que el protagonista anuncia su propia muerte, esta vuelve a estar acompañada de la lluvia, la bruma y la niebla: «La nuit est dense. Les collines sont enveloppées de brume. Il bruine. Le brouillard se défait...» (Del Castillo, 1992: 136). El narrador ha asumido hasta tal punto el papel de monstruo que los demás le han atribuido que decide, precisamente, profanar una tumba para que a él lo maten como a un verdadero monstruo.

En La Guitare la lluvia no sólo representa al agua hostil, sino que también desde las primeras páginas de la novela (en las que el narrador quiere explicar al lector donde se desarrollan los hechos, ya que, según él mismo dice, de donde es uno 
condiciona sus actos («Etre “de” quelque part, as-tu pensé à cela ? C’est important.» [Del Castillo, 1984, 17]), el narrador asocia la lluvia, debido a su carácter persistente, con la monotonía y el hastío: «En Galicie il pleut. Il bruine plutôt. Imagine donc le haut des collines fumantes, l’écume blanche de la mer, la ria enveloppée de brouillard et, par-dessus tout cela, la pluie. Jour et nuit, le monotone glissement de l'eau sur les collines et sur la mer. N'est-ce pas ridicule au Bon Dieu de faire pleuvoir sur la mer ?...» (Del Castillo, 1984: 18).

Y lo que es más, según el narrador, esa monotonía, resultante de la lluvia que no cesa, que de igual manera que cala en los cuerpos, también cala en sus espíritus, volviéndolos grises y aletargados, presas del hastío, es el principio de la morriña, un estado del ánimo (o una manera de ser) típico de los gallegos. Sin embargo, no hay que confundir la morriña con la monotonía o el hastío. El narrador define la morriña como una "nostalgia”, así que el entorno en el que viven los gallegos y que les afecta en su estado de ánimo puede favorecer la existencia de la morriña.

\footnotetext{
Sais-tu ce qu'est le cafard ? La morrina, c'est pire. C'est la nostalgie d’un passé qui n’a jamais existé. [...] Non, tu ne peux pas savoir ce qu'est la morrina. Il faudrait pour cela cette pluie fine, dense, serrée, monotone, qui vous trempe jusqu'aux os ; il faudrait la brume fumant sur les collines ; les vaches mélancoliques et patientes ; l'Océan tout proche qui mugit et qui menace ; il faudrait la faim, la solitude, l'ennui... Tout cela, c'est le début de la morrina et la morrina, c’est toute ma région (Del Castillo, 1984: 21).
}

El hastío que sienten los personajes y la lentitud y la monotonía que caracterizan sus jornadas durante la mayor parte del año pueden considerarse, igualmente, como efectos negativos del elemento acuático en esta novela. La lluvia no es sólo una compañera de la muerte, sino que también debilita la vida de todos los seres vivos de aquellas tierras gallegas.

\section{Conclusión}

En este relato eminentemente lírico se establecen estrechos lazos analógicos entre el paisaje, por un lado, y la personalidad y vivencias del personaje, por el otro, lo que es tónica común de muchas novelas de Michel del Castillo, especialmente las inspiradas en España, como comenta con gran acierto Françoise Dorenlot: «l'écrivain soumet très nettement ses héros au "sortilège” du paysage et du climat» (Dorenlot, 1992: 23).

Esta estrecha relación del personaje con la naturaleza quizás refleje la necesidad efectivamente experimentada por Michel del Castillo de sentirse pertenecer a un mundo, a un país, él que durante años se vio como un exiliado y como un proscrito, según declara en el prólogo de su otra novela Le colleur d'affiches, al referirse a su primera partida forzosa a Francia en 1939, debido a la adhesión de su madre al Frente Popular: «Le conflit qui déchira le pays où je suis né a fait de moi, pendant de longues années, un exilé et un proscrit» (Del Castillo, 1985: 9). Esta trágica vivencia personal se proyecta, sin duda, en La guitare a través del drama del protagonista que, en su propio mundo, vive en el exilio. De hecho, estudiosos de la obra de Michel del Castillo, como Françoise Dorenlot, destacan las marcadas resonancias autobiográficas de sus primeras novelas, entre las que figura La guitare, junto a Tanguy, Gerardo Laïn o Le colleur d'affiches (Dorenlot, 1992: 15).

El agua, elemento primordial del paisaje que configura el decorado de la acción en La guitare, con sus modulaciones, bruma, lluvia o mar, es ensoñada a través de figuraciones de la hostilidad y conflictividad. La naturaleza ofrece el marco de un enfrentamiento continuo entre mar y tierra, entre mar y el hombre, entre bruma o lluvia y el protagonista. Este imaginario del agua evoca, sin duda, el drama de la diferencia del que es víctima el personaje ante la mirada hostil del otro. Una diferencia no aceptada por el pueblo, que acaba generando en él dudas sobre su identidad verdadera. La guitarra, como la escritura, son finalmente recursos a los que recurre para definirse personalmente, para mostrar lo que es pero que los demás le impiden ser.

Asimismo, el imaginario del agua evoca la muerte, la exclusión y la soledad, lo que contribuye a recrear un escenario marcado por la melancolía, el hastío y la desolación en perfecta sintonía con el alma del protagonista quien tratará, aunque en vano, de superar sus males entregándose al juicio de los demás en la Fiesta de las Aguas con ayuda de Linda, su guitarra. Para Michel del Castillo, como para el enano, el arte ofrece un valor salvífico y redentor, un medio de protegerse 
de esa desdicha, de ese abandono y rechazo que realmente sufrió en su infancia y adolescencia entre 1939 y 1953, etapa de la vida que, según él, marca de su fuerte impronta al adulto en que uno se convertirá.

Por tanto, a través de la ensoñación del agua emerge esa crisis identitaria, ese encuentro con la alteridad, evocado aquí por el drama de la diferencia, que tanto caracteriza a las xenografías o voces extranjeras en la literatura francesa, de las que forma parte, sin duda, Michel del Castillo.

\section{Referencias bibliográficas}

BACHELAR, Gaston (1994). L'eau et les rêves. Essai sur l'imagination de la matière. París: Librairie José Corti.

BORNAY, Erika (2001). Las hijas de Lilith. Madrid: Cátedra.

Del Castillo Michel (1984). La guitare. París: Éditions du Seuil, coll. Points.

Del Castillo Michel (1985). Le colleur d’affiches. París: Éditions du Seuil, coll. Points.

DERCHE, Roland (1962). Quatres mythes poétiques (Edipe-Narcisse-Psyché-Lorelei). París: SEDES.

DiJKstRA, Bram (1994). Ídolos de perversidad: la imagen de la mujer en la cultura de Fin de siglo. Madrid/Barcelona: Debate-Círculo de Lectores.

DoRenLOT, Françoise (1992). Michel del Castillo. Amsterdam: Rodopi.

Dottin-Orsini, Mireille (1993). Cette femme qu'ils disent fatale. París: Grasset.

DuRAND, Gilbert (1992). Les structures anthropologiques de l’imaginaire. Introduction à l'archétypologie générale. París: Dunod. 